\title{
Atingindo o consumidor de entretenimento on demand: product placement em House of Cards
}

\author{
Reaching the consumer of entertainment on \\ demand: \\ product placement on House of Cards
}

\author{
Elisa Rocha Celia \\ Graduação em Comunicação Social - Jornalismo pela Pontifícia Universidade \\ Católica do Rio Grande do Sul(2014), graduação em Comunicação Social - \\ Publicidade e Propaganda pela Pontifícia Universidade Católica do Rio Grande do \\ Sul(2007) e mestrado em Comunicação Social pela Pontifícia Universidade Católica \\ do Rio Grande do Sul (2017).
}

\section{RESUMO}

Este trabalho analisa a publicidade na relação dialógica e interativa que se estabelece entre os produtores de séries sob demanda e consumidores alcançados pela estratégia de Product Placement. As teorias são: identidade, posicionamento e imagem de marca, com base em Khauaja e Mattar, Pinho, Tavares, Depexe e Petermann, dentre outros. Como caso, será observada a produção estadunidense "House of Cards", criada para o serviço de streaming Netflix, que se utiliza da técnica para arrecadar fundos. Palavras-chave: product placement; house of cards; comportamento do consumidor; entretenimento; seriado on demand. 


\section{Introdução}

A consciência e a crítica do consumidor caminham em paralelo à evolução tecnológica, e a resistência em relação à publicidade convencional, aliada à facilidade de ignorá-la, faz com que as marcas busquem outras maneiras de dialogar com o cliente e persuadi-lo. De acordo com Rogério Covaleski (2010), o consumidor contemporâneo é mais exigente, mais ativo, questionador, e molda o mercado de acordo com suas preferências e desejos.

O presente trabalho objetiva analisar a presença da publicidade, nesse processo de transição, as suas novas configurações, criando uma relação dialógica e interativa em produtos midiáticos de entretenimento. Como caso para estudo, observaremos a série "House of Cards", criada para o serviço de streaming Netflix. A superprodução se utilizou do Product Placement como estratégia para arrecadar fundos para a elaboração do conteúdo. As marcas se utilizam de inserções, muitas vezes bem discretas, beirando o invisível, dentro do contexto da cena, para que a propaganda não constranja o consumidor e entre na sua mente mesmo que de forma imperceptível.

Para entender o processo, analisaremos conceitos de marca, posicionamento, recepção, de transformação do consumidor e a demanda por novos formatos publicitários, o Netflix, o entretenimento on demand e a série "House of Cards", para então entrarmos na inserção dos produtos na mesma.

\section{Definição, Identidade, Posicionamento e Imagem de Marca}

De acordo com Khauaja e Mattar (2006), uma das maneiras de uma empresa se comunicar com seu público é a partir da marca e de suas ações mercadológicas, para que o consumidor diferencie o produto em relação aos da concorrente e crie um desejo sobre ele.

Para Pinho (1996, p.48), a possibilidade de ser a escolhida é maior sendo a marca mais conhecida, uma vez que o consumidor prefere o produto que é familiar a ele. Já Tavares (1998, p.61), afirma que construir e manter marcas fortes é questão de estratégia, tendo como objetivo dominar o mercado, mesmo que o autor afirme que "não significa que uma marca bem-sucedida necessite um grande volume de vendas em termos absolutos. Às vezes é mais lucrativo ser a número um em um pequeno mercado do que a número três em um amplo mercado."

Na perspectiva do consumidor, para (1998, p.64), a construção de marca procura retratar a expressão do comportamento do público. Nesse aspecto, o fator cognitivo tem importância, pois traz à tona as crenças e o conhecimento do consumidor, que são responsáveis por originar as preferências, criando o comportamento de compra.

O que deve ficar claro para as empresas é ter marca e produto com conceitos bem particularizados, uma vez que o produto tem características e benefícios 
funcionais para o consumidor, já a marca não tem existência física, mas estimula o público a partir de seu posicionamento, alcançando principalmente o emocional. De acordo com Depexe e Petermann (2007, p.2) "A marca é, então, a expressão de vários atributos. Reúne características do produto e valores que o consumidor liga a tais características.”. Muitas vezes, os produtos se sobressaem em função da marca, e não por seus próprios atributos.

Os autores ainda defendem que a partir do instante em que a marca envolve, não só com aspectos gráficos, mas com aspectos psicológicos englobando sentimentos e sensações, ela passa a ter uma identidade. Sendo essa um conjunto de características exclusivas de marca que a empresa procura criar e manter. A união da identidade da marca e da proposta de valor, resultam no posicionamento da marca, que está diretamente relacionado ao fato de despertar desejo no consumidor, destacando-se em relação aos concorrentes.

Tavares (1998, p.65) afirma que a identidade é a forma como a marca deseja ser percebida, e a imagem é como é, de fato, percebida, tendo como influência direta a interação com o público. O autor ainda afirma que a compra é determinada pelo significado que a marca designa ao consumidor.

Entrando no quesito que a imagem define também personalidade, o autor defende que a imagem se forma a partir da definição das estratégias políticas da empresa em relação a produto, promoção, distribuição e preço. Aliados a isso, as impressões deixadas pelos funcionários e ou representantes e vendedores, aparência dos ambientes (lojas, escritórios, fábricas), a relação com os diferentes públicos, direta ou indiretamente, como imprensa, fornecedores, comunidade, entre outros. A imagem a partir de ações no setor de negócios e atividades da região ou país na qual a empresa está inserida, de acordo com valores, crenças e ideologias locais.

Ou seja, para Tavares (1998, p.65), "A imagem decorre da maneira como o público decodifica todos os sinais emitidos por uma empresa por meio de seus produtos, serviços, empregados, programas de comunicação e trato com as questões ambientais."

Ter valor agregado na marca é essencial para a decisão de compra e para obter a lealdade do consumidor. De acordo com Pinho (1996), a valorização é realizada através da criação e da manutenção de um conjunto de características funcionais e aspectos simbólicos conectados à mesma. Tal valor pode ser obtido por meio da Publicidade, a partir do testemunho de personalidades ou pelas características como superioridade tecnológica, segurança e prestígio.

A proliferação de marcas, o alto custo de veiculação de comerciais nos formatos tradicionais, e os novos veículos e meios de comunicação fazem com que as empresas se preocupem além da competitividade, com a maneira pela qual o consumidor vai ser atingido pela sua mensagem. 


\section{Product Placement como ferramenta de Marketing}

Como estratégia de mercado, a partir das mudanças de comportamento do consumidor, principalmente na área de entretenimento, tem sido muito utilizado o Product Placement ou Tie-in (mesmo tendo conceitos distintos, muitas vezes no Brasil é identificada como Merchandising).

A definição de Product Placement para Raul Santa Helena e Antonio Pinheiro (2012) é a inserção de marcas e produtos de maneira sutil e fluida em tramas audiovisuais. O cenário de atuação da estratégia em questão é ampliado por Patrícia Burrowes (2008), incluindo jogos digitais, romances e músicas.

De acordo com Beatriz Braga (2014), essas inserções de marcas e produtos já vem figurando em obras renascentistas de Veneza desde o século XVI, ou seja, não são recentes. Nelas, os produtos simbolizavam superioridade e eram inconfundíveis para a sociedade italiana. As aparições são cada vez mais freqüentes, inclusive no cinema, na televisão, em alguns casos se torna massante demais, como em alguns programas patrocinados.

Em função dessa importante presença na história da televisão e do cinema mundial, e agora também nos serviços on demand, recentemente o Product Placement despertou um maior interesse e a partir de um estudo foi classificado por níveis e por tipos. Os autores que fizeram essa categorização foram Regina Blessa (2006), e Santa Helena e Pinheiro (2012), respectivamente. Os níveis são: Screen Placement (aparição somente visual), Script Placement (citação verbal), Plot Placement (presença integrada à trama) e Story Placement (participação fundamental no enredo). Dentre os tipos, destacamos o Music Placement (utilização e promoção de uma música tema ou artista), o Ad Placement (aparição de uma publicidade da marca), o Destination Placement (divulgação de uma localidade) e o Easter Egg (produto bem escondido).

Essa forma de anúncio mais discreta e pouco invasiva, insere completamente o produto ou a marca no contexto da cena ou da narrativa de qualquer tipo de audiovisual na área de entretenimento. A inserção tenta sempre ser o mais simpática possível, e o menos inconveniente possível, não sendo um anúncio direto.

\section{Entretenimento on demand no Netflix}

Uma das grandes vantagens do serviço on demand é a facilidade da segmentação, de atingir diversos públicos, em qualquer horário. Principalmente pelo conteúdo ser disponibilizado por temporadas, o que não existe possibilidade no caso da televisão, o consumidor tem a chance de assistir quando preferir. Já a televisão, por ter uma grade fechada de programas, e de publicidade, a audiência é completamente dependente do horário do seu público alvo.

A empresa americana Netflix oferece conteúdos audiovisuais on demand, como filmes, documentários e seriados, que podem ser assistidos por streaming, através do site em diversas plataformas, como televisões, computadores, tablets e smar- 
tphones. Com assinatura mensal, o produto é consumido no produto mais conveniente ao espectador, em qualquer local onde o mesmo tenha acesso à internet.

No catálogo do serviço, além de grandes clássicos que podem ser encontrados em outros canais, são oferecidas produções exclusivas, das quais, uma delas, House of Cards, é case deste trabalho. Dessa forma, os produtores possuem uma maior liberdade do que para canais da TV aberta. Sendo assim, de acordo com Chmielewski (2013), a Netflix tem como uma de suas concorrentes, a HBO, que foi a precursora ao permitir essa autonomia.

A estratégia da disponibilização da temporada inteira, faz parte do conceito de binge watching, que de acordo com os dados do Netflix o comportamento dos assinantes de assistirem a vários episódios em sequência está crescendo. Mesmo que a mensuração da audiência não seja de forma tradicional, a oferta de séries próprias também infere no aumento do número de assinantes.

\section{A série House of Cards}

A série norte americana House of Cards foi criada por Beau Willimon para o serviço de streaming Netflix, sendo a primeira exibida em 4k. A trama tem Kevin Spacey como protagonista, no personagem de Francis Underwood, um político ambicioso que almeja um alto cargo público em Washington D.C. A primeira, a segunda e a terceira temporada são compostas por treze episódios cada, elas foram disponibilizadas integralmente em fevereiro de 2013, 2014 e 2015 respectivamente. A Netflix anunciou a confirmação da quarta temporada, ainda sem data definida para lançamento.

Os direitos do romance House of Cards, de Michael Dobbs, foram comprados pela produtora independente Media Rights Capital (MRC), com o objetivo de criar uma série de televisão. A série foi apresentada para várias emissoras, mas o Netflix, com o propósito de lançar um conteúdo próprio, se antecipou em relação aos concorrentes e deu início as etapas de produção, apostando no projeto.

No primeiro momento, o serviço encomendou as duas primeiras temporadas, ou seja, vinte e seis episódios, visando sempre esse novo formato de disponibilizar a temporada completa no mesmo momento. Podemos observar que, sendo assim, se não tivermos a marca inserida dentro da narrativa, não teríamos espaço para elas, faltando recursos para a captação de verba para produção.

\section{Product Placement em House of Cards}

Observar todas as marcas inseridas na narrativa da série House of Cards pode se tornar uma tarefa árdua. Muitas vezes a marca aparece tão sutilmente que leva a pensar, se é mesmo uma ação de marketing, mas como é claro no meio publi- 
citário, nada é de graça, e as inserções são parte sim de uma estratégia.

Sem sair do contexto da narrativa, diversas aparições que não pecam por serem discretas surgem em inúmeras cenas. O espectador frequente tem uma grande possibilidade de ser atingido pela mensagem, uma vez que, por a marca estar presente na trama, pode despertar um desejo de compra, e a simpatia pela marca. Esse formato tende a ser mais efetivo que um comercial de 30", pois por estar na cena, não tem como ser driblado, e que um Merchandising, pois não tende a parecer proposital.

As ações de marketing foram vendidas para marcas mundialmente conhecidas, que apostaram junto com o serviço no sucesso da série. Gigantes do marketing estão presentes nos episódios.

A mais presente, que surge em todos os episódios, e com vários de seus produtos, foi a Apple, inserindo iPhones, iPads, iMacs e Macbooks, sempre em cenas importantes da narrativa, sendo utilizados por protagonistas. Os aparelhos surgem em takes com características próprias da estratégia, para mostrar bem o produto.

A área de eletrônicos se faz presente com diversas marcas. Já no primeiro episódio, em uma festa de réveillon, no telão está sendo transmitida a virada na Broadway, e nos tradicionais letreiros da avenida, surge Toshiba e TDK com leitura bem clara, e a primeira marca segue aparecendo em diversos capítulos. A Sony, assim como a Apple, apresenta mais de um produto, também em destaque. Em uma única cena, o protagonista Kevin Space joga o Kilzone 3, no Playstation, e em uma TV da marca. Além disso, o aparelho PSVita aparece em uma mesa, e Frank Underwood pergunta ao Deputado Russo sobre o mesmo. A Dell também é uma das multinacionais que participa dessa disputa de espaço na história.

Em conflito com um ideal de marketing, onde duas concorrentes não deveriam estar no mesmo espaço, a série mostra que todos têm espaço. A inserção da Blackberry teve um grande destaque por estar presente na última cena da primeira temporada. Além disso, temos mais duas marcas de TVs que se fizeram presentes, LG e Samsung, mesmo que discretas, marcaram presença, a última aparecendo com muita frequência.

Nas cenas de restaurantes, bares e nas mesas de reuniões, dentro do contexto tanto da série, como da vida real, entra a gigante das bebidas, a Coca-Cola, naturalmente chamativa, pela sua identidade. Dividindo as atenções, em algumas cenas vemos latas de Red Bull, gritando para o consumidor, contrariando a inserção da Heineken, que aparece discretamente em um canto de balcão de bar.

Uma cena que chama muito atenção, com inserção clara, e sem a discrição das demais por ser em close, é a câmera que Claire Underwood usa no parque, da Canon. Da mesma forma, sem intenção de disfarçar, diversas imagens nas televisões são da rede CNN.

Inserções, que em nossa opinião são mais discretas, por serem parte do 
figurino, aparecem durante as práticas de esporte do casal protagonista, utilizando produtos Nike, e os diversos modelos de óculos RayBan vestidos pela Claire Underwood. Em muitas cenas podemos ver carros onde a marca é claramente reconhecida, e podemos perceber a presença da Toyota, da Chevrolet, da Alfa Romeo e da Ford. Ainda podemos identificar marcas como WaterRower, Honey Bunch of Oats, Skin Plus Milk, Louboutin, Panasonic, Visa, Mastercard, American Express, Hellmann's, Pizza Hut, John Deere e Marlboro.

\section{Considerações finais}

É possível deduzir que essa ferramenta de ligação entre as marcas e os consumidores, sempre existiu, mesmo que de maneira informal na indústria cinematográfica. Seja em negociações, trocas de gentilezas, já visando esse objetivo de inserção, pelo lado das empresas, e a necessidade de objetos para compor a cena, sem verba, pelo lado da produção.

Embora no Brasil a estratégia ainda seja chamada de merchandising, existem algumas diferenças em relação a Product Placement. Fernando Palacios, explica que

"A inserção de um produto e sua marca dentro de um filme é tecnicamente chamada de product placement. Merchandising é outro conceito, a comunicação da marca dentro do ponto de venda. Se os conceitos são tão distantes um do outro, de onde vem a confusão? Pois bem, existe uma lenda de que foi uma emissora que confundiu a cabeça de todo o mundo quando resolveu promover seu serviço de product placement e, na ocasião, teria dito que mais do que placement, aquilo era merchandising, já que a novela também era um ponto de venda e as pessoas compram tudo o que ali aparece" (Fernando Palacios, in AdNews)

Para Santa Helena (2012), independente do nome, o ideal é que tanto a marca, como a produção saibam utilizar a ferramenta, sem faltar com respeito ao público e ao conteúdo, sendo sempre adequado a cena inserida.

Após analisar as três temporadas de House of Cards, Podemos notar a existência de todos níveis de Product Placement, como Screen Placement, Script Placement, Plot Placement e os tipos Ad Placement e Easter Egg. E percebemos que com poucas exceções, a produção soube como encaixar as marcas dentro da sua narrativa, muitas delas passando que quase invisíveis.

Acreditamos que esse trabalho seja o início de uma pesquisa da presença cada vez maior das marcas nas formas de entretenimento, uma vez que o comportamento do consumidor em relação aos hábitos de consumo de conteúdo vem mudando, e tem tido cada vez mais exigência. 
Referências

BLESSA, Regina. Merchandising no ponto-de-venda. São Paulo: Atlas, 2006.

BRAGA, Beatriz Bezerra; CARREIRO, Rodrigo Octavio D’Azevedo; Comunicação, Consumo e Entretenimento: a Construção Diegética e Subjetiva da Marca em Obras Audiovisuais Através do Uso do Product Placement. In. $4^{\circ}$ Congresso de Comunicação e Consumo, São Paulo, 2014. Disponível em http://www.espm.br/ download/Anais Comunicon 2014/gts/gt seis/GT06 BEATRIZ BRAGA.pdf . Acesso em 04 dez. 2015.

BURROWES, Patrícia. Cinema, entretenimento e consumo: uma história de amor. Porto Alegre: Revista FAMECOS, Abril de 2008.

CHMIELEWSKI, Dawn C. Netflix executive upends Hollywood. LAtimes.com, 2013. Disponível em < http://www.latimes.com/entertainment/envelope/cotown/ la-et-netflix-ted-sarandos-20130825-dto-htmlstory.html> Acesso: 06 dez 2015.

COVALESKI, Rogério. Publicidade: evoluções na teoria, transições na prática. In: KELLER, Kátia; SATLER, Lara (Orgs.). Século XXI: a publicidade sem fronteiras? Goiânia: Editora da PUC de Goiás, 2011. Publicidade Híbrida. Curitiba: Maxi Editora, 2010

DEPEXE, Sandra Dalcul; PETERMANN, Juliana. O raio-x da verdade da marca. Trabalho apresentado ao GT Publicidade e Propaganda, do VIII Congresso Brasileiro de Ciências da Comunicação da Região Sul. Universidade Federal de Santa Maria. 2007. 11 p. In: Intercom - Sociedade Brasileira de Estudos Interdisciplinares da Comunicação. Santa Maria, 2007. Disponível em: http://www.intercom.org.br/ papers/regionais/sul2007/resumos/R0440-3.pdf Acesso em 5 dez. 2015.

DICTIONARY REFERENCER. Binge watching Disponível em Acesso: 24 ago. 2014. DICTIONARY REFERENCER. Video on demand. Disponível em http:// dictionary.reference.com/browse/binge\%20watching?s=t Acesso em: 05 dez. 2015.

DICTIONARY REFERENCER. Video on demand. Disponível em http://dictionary.reference.com/browse/video-on-demand Acesso em: 05 dez. 2015.

KHAUAJA, Daniela Motta R.; MATTAR, Fause Najib. Fatores de marketing na construção de marcas sólidas: estudo exploratório com marcas brasileiras. Revista de Gestão USP. São Paulo, v. 13, n. 4, p. 25-38, out/dez 2006.

PINHO, José Benedito. O Poder das Marcas. 3. ed. São Paulo: Summus Editorial, 1191996.152 p.

SANTA HELENA, Raul; PINHEIRO, Antonio. Muito além do Merchan!. Rio de Janeiro: Campus, 2012.

STÜRMER, Adriana; SILVA, Giana Petry Dutra da; Do DVD ao online strea- 
ming: a origem e o momento atual do Netflix. In. XXXVIII Congresso Brasileiro de Ciências da Comunicação . Rio de Janeiro, 2015. Disponível em http:// portalintercom.org.br/anais/nacional2015/resumos/R10-2939-1.pdf . Acesso em 04 dez. 2015.

TAVARES, Mauro Calixta. A força da marca: como construir e manter marcas fortes. São Paulo: Harbra, 1998. 220 p.

Site AdNews - Meu nome é Placement, Product Placement - Disponível em $<$ http://www.adnews.com.br/index.php?url=revista/meu-nome-e-placement-product-placement> Acesso em 08 dez. 2015. 